Case report

\title{
Percutaneous closure of a postoperative residual atrial septal defect
}

\author{
Zehra Erkal *, Nermin Bayar, Göksel Çağırcı, Şakir Arslan \\ Antalya Education and Research Hospital, Cardiology Department, Antalya, Turkey
}

\section{A R T I C L E I N F O}

\section{Article history:}

Received 5 January 2017

Accepted 19 January 2017

Available online 23 January 2017

\section{Keywords:}

ASD

Percutaneous closure

Residual defect

\begin{abstract}
A B S T R A C T
Atrial septal defect (ASD) is the most common adult congenital heart disease. The aim of the treatment of this disease is the surgical or percutaneous closure of the defect. Although surgical method has been used for a long time, primarily percutaneous closure is preferred currently in many centres for appropriately selected patients. Percutaneous closure can be used for the primary treatment of newly diagnosed patients and also for cases who are found to have residual defect after surgical closure. In the literature, however, only a limited number of patients who underwent percutaneous ASD closure were reported. In this report, we present our case who was successfully treated through percutaneous closure of postoperative residual ASD.

(C) 2016 The Society of Cardiovascular Academy. Production and hosting by Elsevier B.V. This is an open access article under the CC BY-NC-ND license (http://creativecommons.org/licenses/by-nc-nd/4.0/).
\end{abstract}

\section{Introduction}

Atrial septal defect (ASD) is the most common adult congenital heart disease. ${ }^{1}$ Open heart surgery has been performed for its treatment for many years. ${ }^{2}$ Today, however, percutaneous closure of ASD is preferred for appropriate patients. ${ }^{3}$ During follow-up, residual defects may develop in 7-8\% of patients who have undergone surgery. ${ }^{4}$ Medical follow-up is sufficient for hemodynamically insignificant residual defects while reintervention is needed for large defects. In the literature, there are only a limited number of patients reported to have developed postoperative residual defects and undergoing percutaneous closure.

\section{Case report}

A twenty-five year old male patient presented to our outpatient clinic with the complaint of shortness of breath and fatigue. His history revealed that he underwent patch repair for ASD and mitral ring repair due to secundum ASD and cleft mitral valve 6 months before. During his physical examination, fixed splitting on S2 was detected. His electrocardiography showed sinusal arrhythmia and right bundle block. Transthoracic echocardiography was performed for the patient; a 14-mm defect was detected on interatrial septum and the color Doppler showed left-to-right shunting). Value of $\mathrm{Qp} / \mathrm{Qs}$ is 2.9. Mitral valve structure was normal (Fig. 1). Then transesophageal echocardiography was performed; which showed $14 * 12 * 12$-mm residual defect on the interatrial septum. The morphological features and rims of the residual ASD were considered to be appropriate for percutaneous closure. Under

\footnotetext{
Peer review under responsibility of The Society of Cardiovascular Academy.

* Corresponding author.

E-mail address: zehraerkalkard@hotmail.com (Z. Erkal).
}

deep sedation, percutaneous ASD closure was performed successfully for the patient with 17-mm Amplatzer occluder under transesophageal echocardiography. $34 \mathrm{~mm}$ balloon sizing catheter used in closure. After the procedure, the control echocardiography showed that the device occluded the defect completely and the color Doppler did not show any shunting (Fig. 2). There is no difference from routine percutaneous ASD closure. The patient was discharged on the following day without any problem.

\section{Discussion}

Secundum ASD is the most common congenital heart disease among adults. ${ }^{2}$ Patients with ASD are usually asymptomatic at early stages. The volume loading of the right atrium and right ventricle increases in time and pulmonary arterial hypertension develops. The progression of pulmonary hypertension results in right ventricular insufficiency and Eisenmenger syndrome. Furthermore, arrhythmia and paradoxical embolism are common in these patients. Therefore, the defect should be closed as soon as the diagnosis is established if there is no contraindication. $^{5}$

Surgical closure is the conventional method for the treatment of ASD. In this method, the defect is occluded through primary sutures or patch. Mortality and morbidity rates are low in this method compared to coronary artery surgery. However, it has some disadvantages such as sternotomy-thoracotomy requirement, postoperative pain, infection and permanent scar tissue. ${ }^{5}$

Today, the other defects except secundum ASD are treated surgically. However, transcatheter occlusion is preferred to surgical closure in patients with secundum ASD who are suitable for percutaneous closure. To determine the eligiblity of patients for percutaneous closure; the size of the defect, length of the total septum, sufficiency of the rims and 


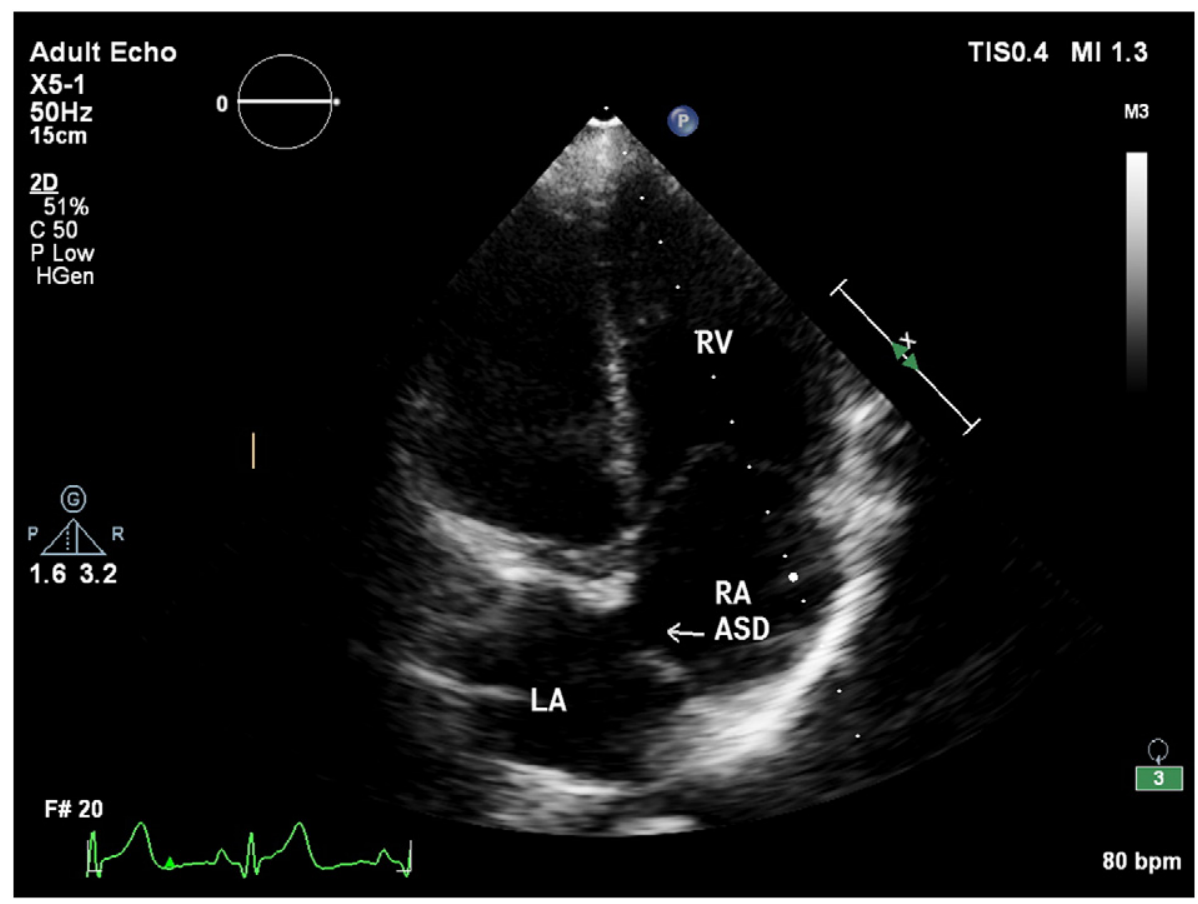

Fig. 1. Echocardiographic view of residual atrial septal defect.

comorbid congenital anomalies are assessed on transesophageal echocardiography. ${ }^{6}$

Percutaneous ASD closure is usually a safe procedure. However, major complications may rarely develop after transcatheter ASD occlusion, which includes perforation of the atrial wall, atrial arrhythmias and embolization of the device. The rate of such complications is less than $2 \%$. The complication rates increase as the size of the device used gets bigger. ${ }^{6}$
Postoperative residual defects rarely develop in patients who are operated for secundum ASD. The development of the residual defect may be associated with the problems in the surgical technique or degeneration of the graft. The presence of pulmonary hypertension and arrhythmia is important for the choice of treatment in patients who develop postoperative residual ASD. ${ }^{7}$ The hemodynamic significance of the shunt in patients who have residual ASD and their eligibility for percutaneous closure should be assessed. Like in our case, percutaneous

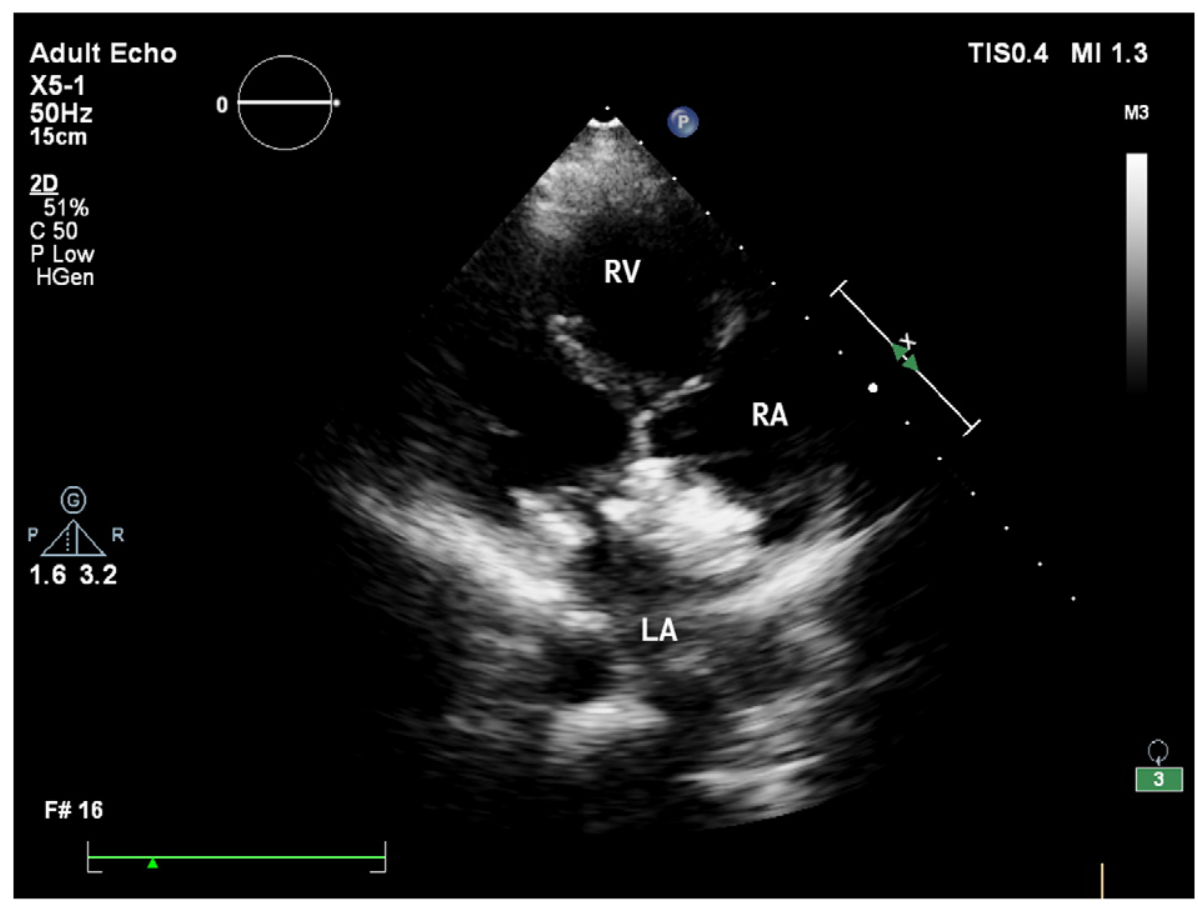

Fig. 2. Echocardiographic view of amplatzer occluder in intraatrial septum. 
closure should be preferred to surgery for appropriate patients since it is a less invasive method.

\section{Conclusion}

The eligibility of the patients who develop postoperative residual ASD for percutaneous closure should be assessed taking into account the hemodynamic significance of the shunt and the morphological features of the defect. Percutaneous closure is a safe and effective treatment option if the morphological features are appropriate in these patients like newly diagnosed patients with secundum ASD.

\section{Conflict of interest}

The authors report no relationships that could be construed as a conflict of interest.

\section{References}

1. Meyer RM, Kurz DJ, Bernheim AM, Kretschmar O, Eberli FR. Efficacy and Safety of Transcatheter Closure in Adults with Large or Small Atrial Septal Defects. , 5Springer plus; 2016;1841.

2. Bialkowski J, Karwot B, Szkutnik M, Banaszak P, Kusa J, Skalski J. Closure of atrial septal defects in children: surgery versus Amplatzer device implantation. Tex Heart Inst J 2004

3. Harper RW, Mottram PM, McGaw DJ. Closure of secundum atrial septal defects with the Amplatzer septal occluder device: techniques and problems. Catheter Cardiovasc Interv 2002;57:508-524.

4. Murphy JG, Gersh BJ, McGoon MD, et al. Long-term outcome after surgical repair of isolated atrial septal defect. Follow-up at 27 to 32 years. N Engl J Med 1990;323:1645-1650

5. Du ZD, Hijazi ZM, Kleinman CS, Silverman NH, Larntz K, Investigators A. Comparison between transcatheter and surgical closure of secundum atrial septal defect in children and adults: results of a multicenter nonrandomized trial. J Am Coll Cardiol 2002;39:1836-1844.

6. Amin Z, Hijazi ZM, Bass JL, Chaetham JP, Hellenbrand WE, Kleinman CS. Erosion of Amplatzer septal occluder device after closure of secundum atrial septal defects: review of registry of complications and recommendations to minimize future risk. Catheter Cardiovasc Interv 2004;63:496-502.

7. Kumar SM, Bijulal S, Krishnamoorty KM. Percutaneous transjugular device closure of postopeartive residual atrial septal defect. J. Invasive Cardiol. 2013;25(4):E78-E80. 